Thorax (1970), 25, 762.

\title{
A case of chronic paraffin pneumonitis
}

\author{
R. SALM and E. W. HUGHES \\ Department of Histopathology, Royal Cornwall Hospital (Treliske), Truro, \\ and Tehidy Hospital, Camborne, Cornwall
}

A case of chronic paraffin pneumonitis is reported which had remained undiagnosed during life. The patient, a woman aged 48 at death, was subsequently found to have been taking regularly very large doses of liquid paraffin during a decade or more. The main clinical, radiological and histological features are discussed.

\begin{abstract}
-Much of what follows has been said before, but it would appear that any amount of reiteration is justified as long as the same mistakes continue to occur.'
\end{abstract}

H. A. Buechner and L. E. Strug (1956)

Although the syndrome of an exogenous lipoid pneumonia due to aspirated liquid paraffin has been established for some four decades, it is evident from many of the published reports, mainly in the American literature, that the diagnosis is still frequently being missed unless investigations are deliberately undertaken with this possibility in mind. Rewell (1947) published the first probable case from this country, but since then there have been but few observations in the British Isles (Forbes and Bradley, 1958 ; Siddons, 1958 ; Cotton and Lloyd, 1960; Elston, 1966). Forbes and Bradley (1958) emphasized that the aspiration of oil was not considered in the aetiology of any of their four cases during life, and stated that diagnosis was difficult even at necropsy.

It is for this reason that we wish to draw once more attention to the entity by recording a case of chronic lipoid pneumonia which-unknown to the patient's medical advisers-was due to prolonged self-administration of large doses of liquid paraffin. Once again the nature of the illness remained undiagnosed until after death.

\section{CASE REPORT}

Mrs. E. M. W., a British-born housewife, first attended in May 1967 at the age of 46 , when she complained of recent cough and night sweats. In the previous six months she had had two attacks of bronchitis, both of which had been slow to clear in spite of antibiotics. She stated that she had been treated for pulmonary tuberculosis in a sanatorium in 1939, and that she had received treatment for ulcerative colitis for 24 years following diagnosis in a teaching hospital.

When admitted she was pale, tense and depressed. It was learnt that she had been taking amphetaminecontaining drugs for 14 years, but she refused to consider either withdrawal of the drug or admission to a psychiatric ward. At this stage early finger clubbing was noted, but there were no other respiratory signs.

A chest radiograph showed discrete coarse mottling with apparently calcified nodules and a smaller area of fine punctate mottling mainly, though not exclusively, in the right middle lobe (Fig. 1).

Laboratory investigations: haemoglobin $117 \%$; WBC $12,600 /$ c.mm. with a normal differential count ; ESR $5 \mathrm{~mm}$. in one hour ; Mantoux 1/1,000 and 1/100 negative; $\mathrm{FEV}_{1} 1.7$ litres and FVC 2.1 litres (predicted normal figures: $2 \cdot 8$ litres and 3.3 litres respectively); sputum mucopurulent, no pathogenic organisms; R.A. latex fixation test negative; L.E. antibody test negative; serum proteins: total protein $7 \cdot 0$ g. $/ 100 \mathrm{ml}$; albumin $3.6 \mathrm{~g} . / 100 \mathrm{ml}$; globulins 3.2 g. $/ 100 \mathrm{ml}$; $\mathrm{A} / \mathrm{G}$ ratio $1 \cdot 1 / 1$.

Without specific treatment her chest condition quickly improved, but her mental state precluded further investigations and she left hospital before a diagnosis could be made. Two months later (August 1967), when seen as an out-patient, she complained of orthopnoea, but cough was denied and she was less nervous. In September 1967 she was referred by her doctor because of recurrent diarrhoea. Sigmoidoscopy showed minimal evidence of colitis and it was considered that she was recovering from another 'exacerbation of symptoms'.

In June 1969 she was readmitted with a two months' history of increasing breathlessness, rightsided pleuritic pain and a moist cough not responding to ampicillin therapy. She also complained of diarrhoea and was having six to seven bowel actions a day. Stools were semi-formed and mucus was present but no blood. It was obvious that her condition had deteriorated and clinical features now inclu- 


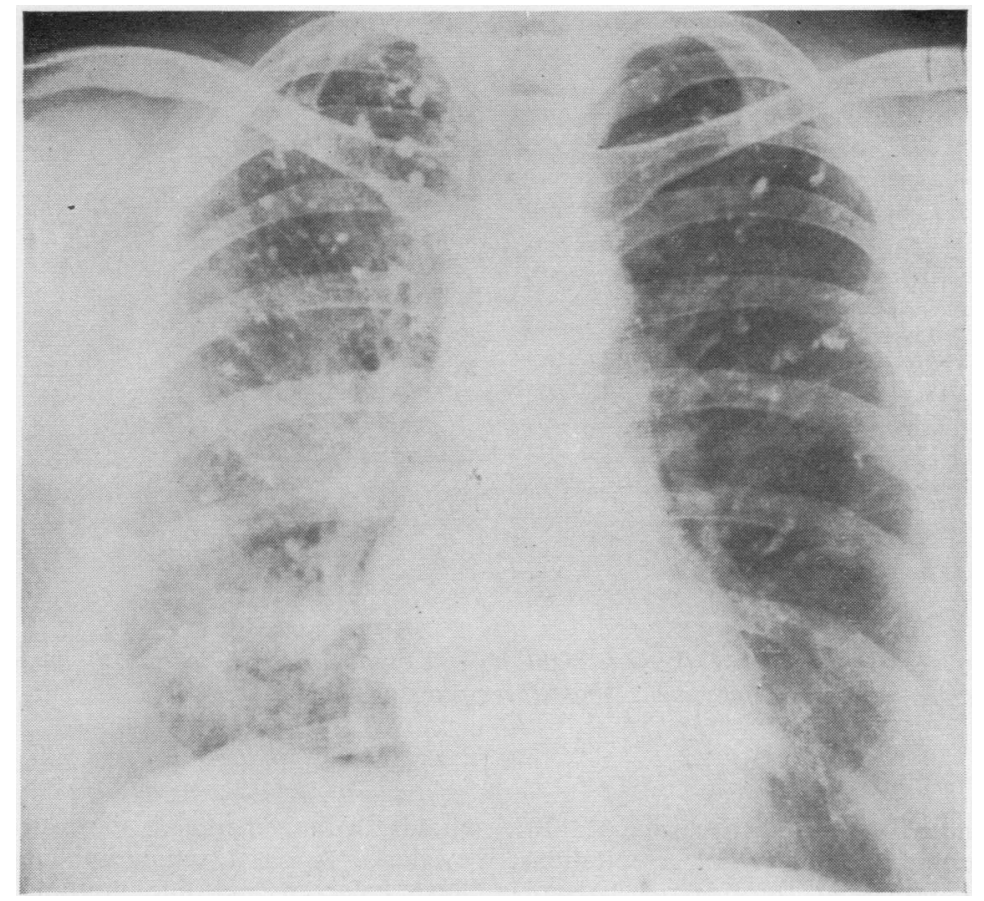

FIG. 1. Chest radiograph May 1967. Fine mottling in right mid zone and scattered calcified nodules.

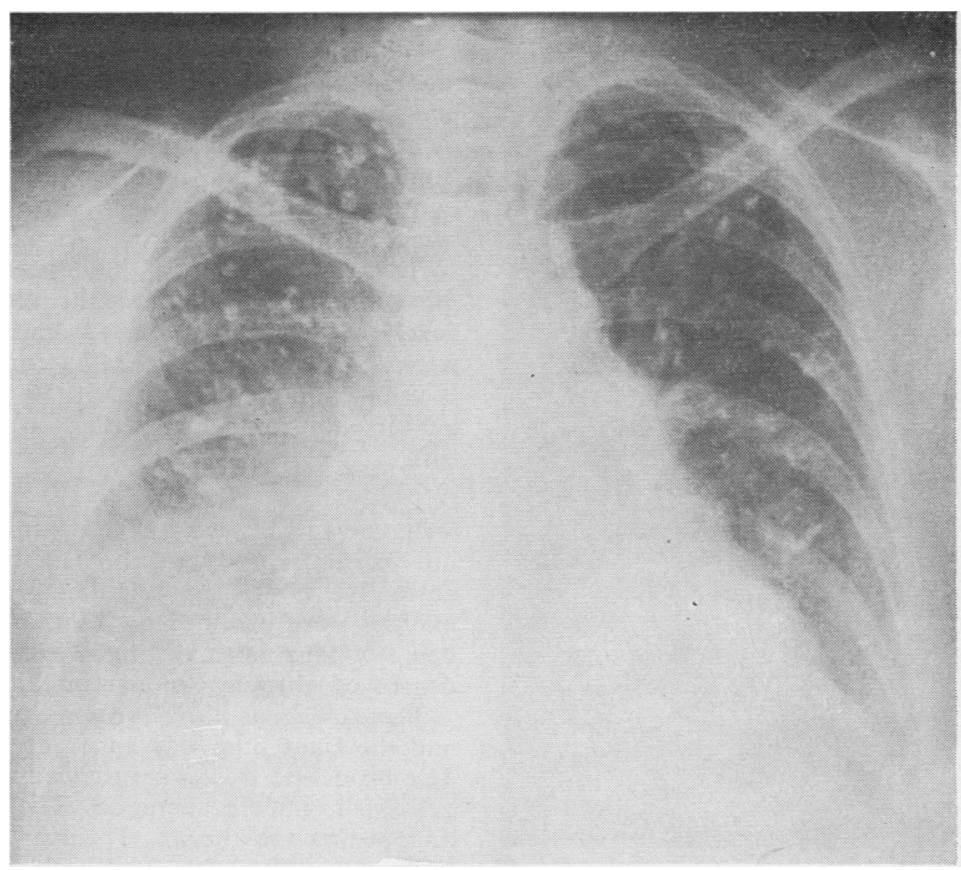

FIG. 2. Chest radiograph June 1969. Heart enlarged. The fine mottling has increased in the lower and mid zones of the right lung and has extended to the left lower zone. 


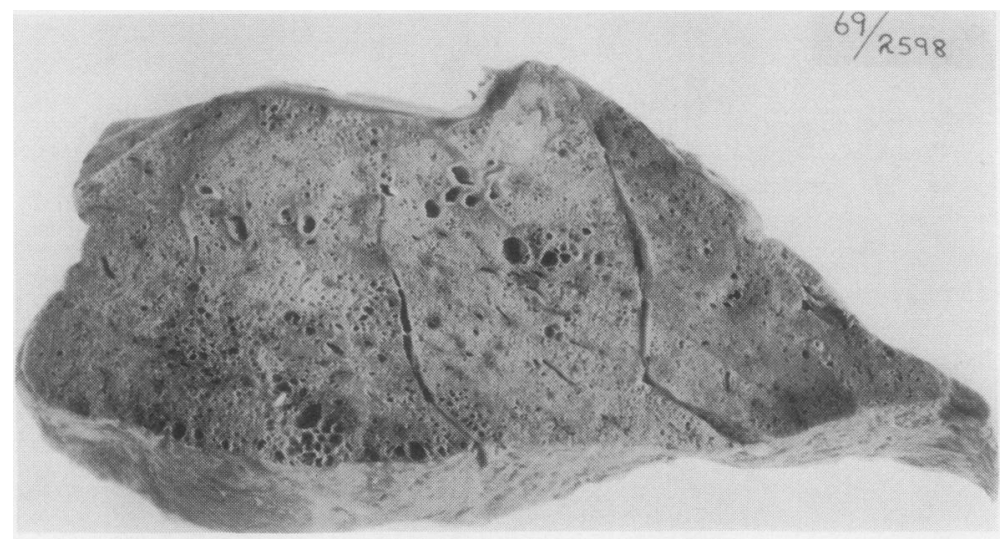

FIG. 3. Posterior cut through right lung. Consolidation of lung with mainly subpleural cystic emphysema. About three-fifths of natural size.

ded pallor, tachypnoea, a sinus tachycardia of $120 /$ minute, finger clubbing, right basal crepitations, ankle oedema and prolapsed third-degree haemor-

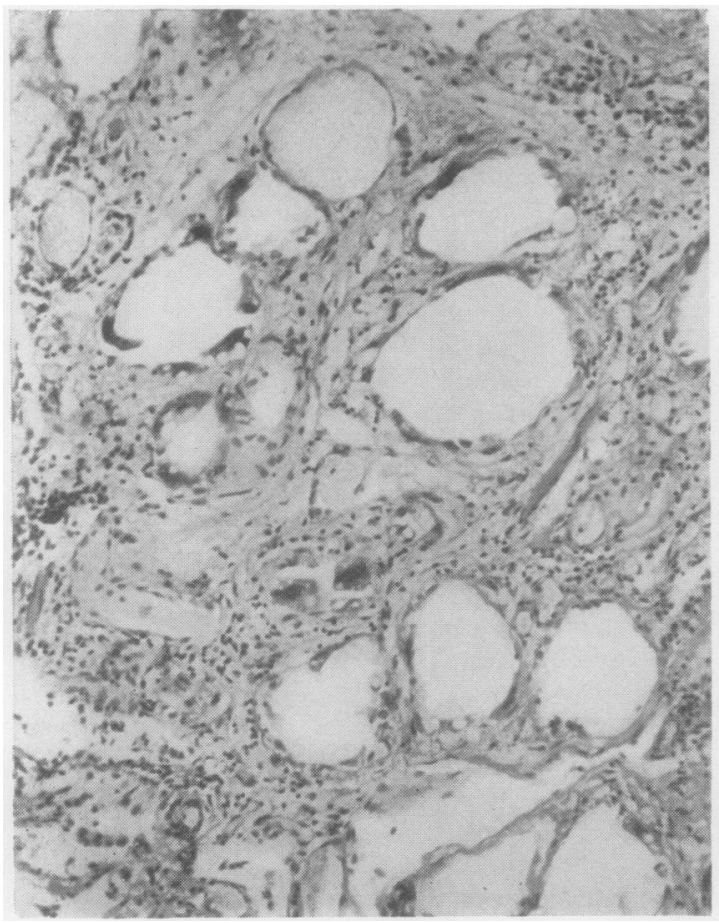

FIG. 4. Right lung. Cribriform pattern due to large oil vacuoles with giant cells along their peripheries. Haematoxylin and eosin. $\times 110$. rhoids with superficial ulceration. There was no cyanosis. A chest radiograph showed the heart to have enlarged and fine mottling to have extended to the mid and lower zones of the left lung (Fig. 2).

Laboratory investigations: haemoglobin $80 \%$; WBC $8,000 /$ c.mm. ; ESR $30 \mathrm{~mm}$. in one hour ; sputum -no bacterial growth; $p \mathrm{H} 7 \cdot 47 ; \mathrm{PCO}_{2} 27 \mathrm{~mm}$. $\mathrm{Hg}$; Po, $53 \mathrm{~mm}$. $\mathrm{Hg}$.

Treatment with oxygen, tetracycline, diuretics and digoxin had little effect. It was considered that her malady was a form of fibrosing alveolitis and treatment with corticosteroids was started, but she died suddenly one week after admission at the age of 48 , two and a half years after the start of her respiratory symptoms.

After the diagnosis had been established post mortem relevant enquiries of the patient's husband revealed that the deceased had been taking each week 1 litre of liquid paraffin (or about $150 \mathrm{ml}$. per day) by mouth for more than 10 years on account of her haemorrhoids, in order to keep her motions soft.

NECROPSY (P.M. 69/118) Examination was carried out 32 hours after death. The body was that of a normally nourished middle-aged female. Abnormalities were confined to the thorax, all other organs being within normal limits except for a moderate degree of chronic venous congestion of the spleen

There was a fibro-fibrinous adhesive pericarditis, and the right lung was adherent to the costal pleura. The bronchial tree was inflamed and contained much yellowish mucoid secretion. The left lung collapsed on opening the thorax. The right lung was enlarged, uniformly firm-elastic, and both lungs were congested and oedematous. When sliced, the right lung showed patches of fine, yellowish, spongy fibrosis (Fig. 3). There were similar though less pronounced changes 


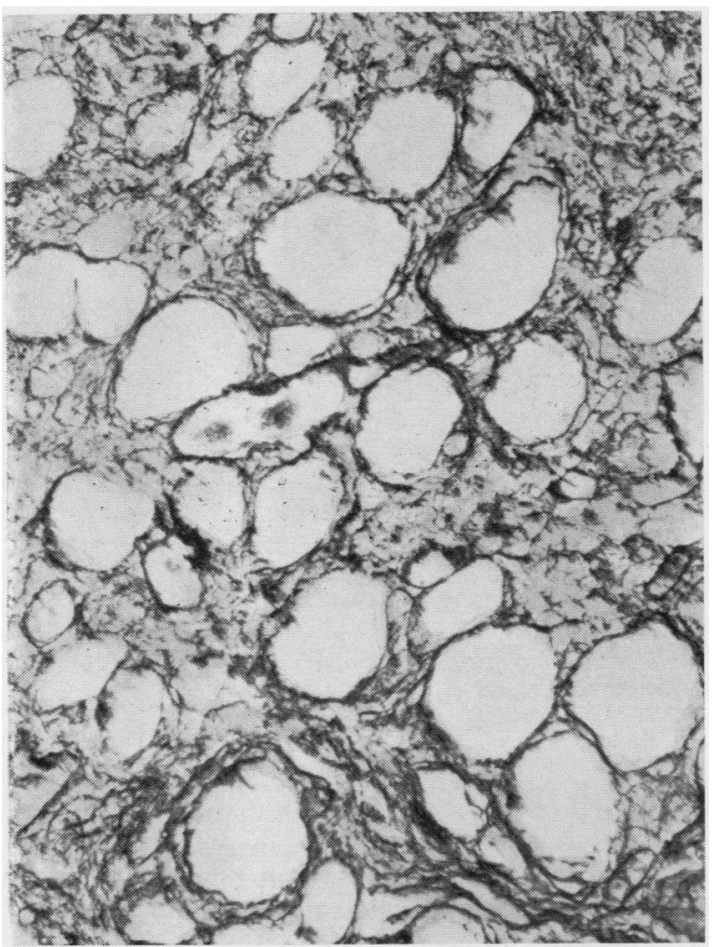

FIG. 5. Similar field to that shown in Fig 4, silver impregnation. Modified Gordon and Sweet. $\times 110$. in the left lung. The pleural surfaces were smooth, and though there was some patchy subpleural bullous emphysema, a hobnail pattern due to subpleural cystic spaces was absent. Both lungs contained scattered bony hard nodules measuring up to $1 \mathrm{~cm}$. in diameter, but there was no evidence of active or healed tuberculosis, and the hilar lymph nodes were only slightly enlarged.

MICROSCOPICAL EXAMINATION (69/2598) Both lungs showed widespread changes of a diffuse chronic pneumonitis which, in many areas, was non-specific. Elsewhere the tissues were fibrotic and incorporated many round empty spaces, producing a cribriform pattern (Fig. 4), which was well demonstrated in silver impregnations (Fig. 5). Frequently these spaces were surrounded by swollen macrophages, often with multiple nuclei and foamy cytoplasm (Fig. 6). Similar cells ringed the smaller bronchi and filled the alveoli in many areas. There was a patchy lymphocytic infiltration of the alveolar walls and septa. Frozen sections stained with Scharlach $\mathbf{R}$ demonstrated that the large macrophages were lipophages. Free lipid globules were also present within the alveoli, and a few were present within the hilar lymph nodes. The fatty material was not stained by osmium tetroxide and no anisotropic material was demonstrable in polarized light. Squamous metaplasia of the bronchial epithelium was discernible in a few areas. The hard nodules found scattered in both lungs proved to consist of a core of inspissated mucous secretion surrounded by an osseous shell (Fig. 7) with, occasionally, some fatty marrow.

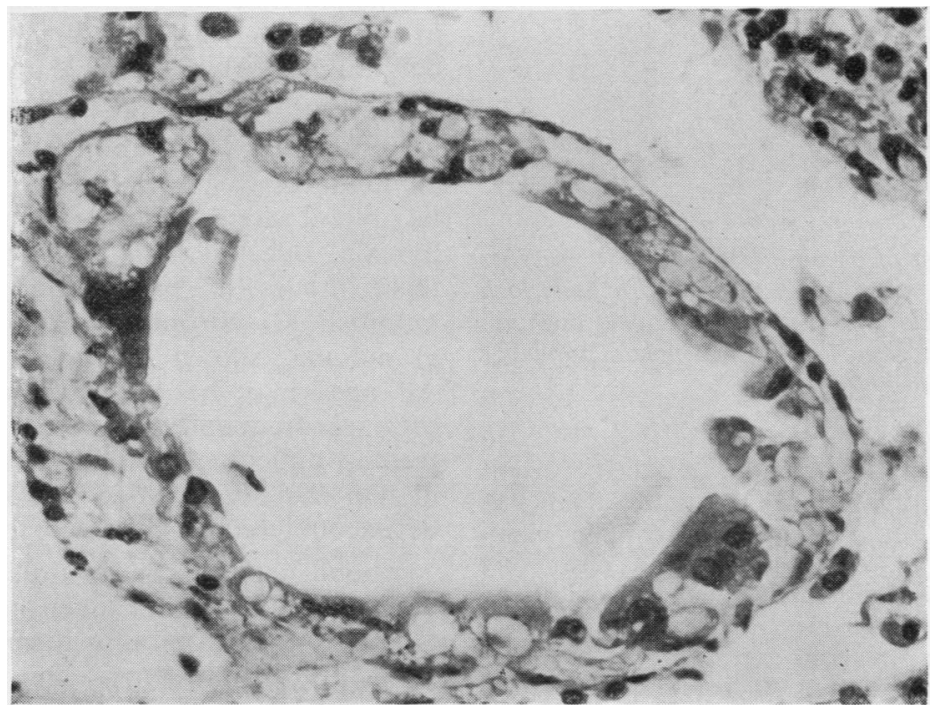

FIG. 6. High-power view of foamy macrophages arranged around a single oil vacuole. Haematoxylin and eosin. $\times 430$. 


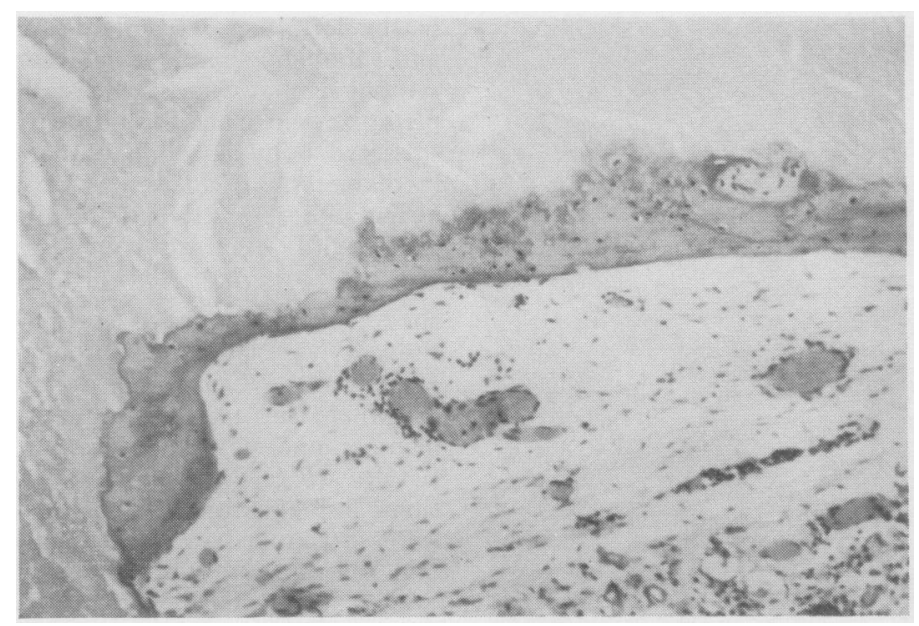

FIG. 7. Periphery of hard pulmonary nodule showing inspissated mucous secretion surrounded by osseous shell. Haematoxylin and eosin. $\times 110$.

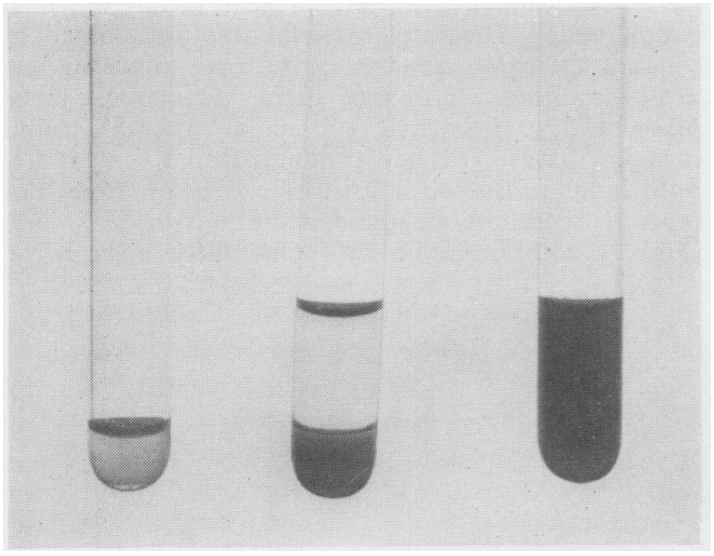

FIG. 8. Solubility test of paraffin oil. From left to right: (1) clear transparent oil; (2) oil stained with Scharlach $R$-no mixing of fluids after shaking with cold acetone; (3) oil stained with Scharlach $R$-complete solubility after shaking with cold chloroform.

EXAMINATION OF FATTY MATERIAL A slice of right lung was cut into small blocks and all fluid was expressed manually. It was noted to contain many small oil droplets. After centrifuging a clear oily supernatant liquid was obtained which proved to be chemically and optically inert. It stained with fat stains, was soluble in cold chloroform, but was insoluble in cold acetone (Fig. 8), reactions which are those of liquid paraffin (Wagner, Adler, and Fuller, 1955). In our hands this reaction proved not to be applicable to histological sections.

\section{DISCUSSION}

Although the subject has been well reviewed in the past (Freiman, Engelberg, and Merrit, 1940 ; Annotation, Lancet, 1951; Volk, Nathanson, Losner, Slade, and Jacobi, 1951 ; Buechner and Strug, 1956 ; Meyers and Griffith, 1955), it may be helpful to re-emphasize the main features of the condition, particularly since a recent report has stated that the consumption of liquid paraffin in the United Kingdom still exceeds 30,000 gallons per annum (Annotation, World Medicine, 1970).

Clinically, paraffin pneumonitis is often asymptomatic, but about half of the patients complain of dyspnoea, cough, sputum which may be blood-stained, chest pain and intermittent pyrexia. Buechner and Strug (1956) distinguished three modes of presentation: (1) acute pneumonitis ; (2) chronic pneumonitis; (3) localized granuloma, shown on radiological examination. All ages may be affected, but the extremes of life are frequently involved, viz., infants with feeding difficulties and the debilitated chronically ill. On the other hand, typical lung lesions may be encountered in otherwise healthy adults.

About half of the recorded cases have been due to liquid paraffin taken by mouth as a laxative. In the past, paraffin formed the base of nose drops and throat sprays, and it is still sometimes being used as a lubricant for oesophageal bougies and gastric tubes. A large variety of other mineral oils, including atomized penetrating oil (Schwindt, 
Barbee, and Jones, 1967), as well as vegetable oils (olive, castor, poppy seed oils) and animal fats (milk, butter, egg yolk, fish oils), have also been implicated (Buechner and Strug, 1956).

Since paraffin oil suppresses the normal cough reflex some of the ingested oil may run down from the pharynx into the trachea and bronchial tree, particularly when the patient is lying supine in bed at night. The ciliary action of the respiratory epithelium and the normal outward flow of mucus is inhibited and eventually the oil reaches the alveoli.

Here the resulting tissue reaction will vary according to the nature of the lipids. Most neutral vegetable oils do not elicit any reaction, the oil being removed by expectoration (Pinkerton, 1928 ; Paterson, 1938).

Animal fats are rapidly hydrolysed by the pulmonary lipases and the liberated fatty acids produce necrosis followed by fibrosis, the degree of the damage being dependent on the amount of free fatty acids present and on the speed of the hydrolysis.

Mineral oils do not produce necrosis. They cannot be hydrolysed but are quickly emulsified and then taken up by macrophages. Although a few oil droplets may penetrate into the peribronchial lymphatics and may reach the hilar and abdominal lymph nodes (Pinkerton, 1927, case 6; Steinberg and Finby, 1956 ; Siddons, 1958, case 3 ; Cotton and Lloyd, 1960) or liver and spleen (Pinkerton, 1927, case 6; Volk, Losner, Lewitan. and Nathanson, 1955 ; Steinberg and Finby, 1956), most of the mineral oil will remain intracellularly within the alveoli. As the macrophages disintegrate after some time the oil is liberated, but since it depresses ciliary action it is not expectorated but again ingested by macrophages, thus setting up a vicious circle which accounts for the chronicity of the condition (Volk et al., 1951). After a few months diffuse interstitial fibrosis will ensue.

All parts of the lungs may be involved, but the apico-lower and posterior basal segments of both lower lobes, and especially of the right lung, are most often the site of a lipoid pneumonia (Buechner and Strug, 1956 ; Steinberg and Finby, 1956 ; Schwindt et al., 1967). Macroscopically the lungs display greyish-pink or greyish-yellow consolidations and are moderately firm and spongy, and milky fluid can occasionally be expressed from the cut surfaces (Freiman et al., 1940).

Microscopically the features are those of a lipid pneumonia with patchy fibrosis and incorporating oil vacuoles, thus producing the sievelike pattern of a 'paraffinoma'. Whilst some areas may exhibit a non-specific pneumonitis, others are characterized by large amounts of intra- and extra-cellular oil. Proof that the oil in question is indeed paraffin is difficult since mineral oils are chemically inert and cannot be saponified. In frozen sections paraffin oil stains an orangy hue with Sudan or Scharlach $R$, but, in contrast to vegetable and animal fats, paraffin is not stained with osmium tetroxide (Pinkerton, 1927 ; Forbes and Bradley, 1958). If sufficient oil can be obtained use may be made of the observation that paraffin oil is soluble in cold chloroform but not in cold acetone (Wagner et al., 1955).

Radiologically the lung changes are seldom specific. In the early stages the chest radiograph shows a small area of mottling, often localized to a bronchopulmonary segment. The mottling may be fine or 'punctate', and indistinguishable from that seen in fibrosing alveolitis, or may have a more nodular appearance of rosette-like clumps. Weill, Ferrans, Gay, and Ziskind (1964) have experimentally produced similar radiological opacities by the intrabronchial instillation of mineral oil in anaesthetized dogs and suggest that this appearance may be of diagnostic value. Later the mottling becomes more diffuse, producing a ground-glass appearance, or a fine reticular pattern develops due to interstitial fibrosis. A solitary oil granuloma presents on radiological examination as an irregular nodular opacity suggestive of a bronchial carcinoma. Pleural effusions are not a feature (Volk et al., 1951), but a characteristic finding has been the unchanging nature of the lesions over months and even years (Miller, Bader, Bader, Teirstein, and Selikoff, 1962). In the differential diagnosis fibrosing alveolitis, sarcoidosis, alveolar proteinosis, haemosiderosis, unresolved pneumonia and bronchial carcinoma must be considered.

Respiratory function tests show a restrictive type of ventilatory defect with a reduced forced vital capacity, a decreased $\mathrm{Po}_{2}$ on exercise, and a decreased transfer factor without airways obstruction (Weill et al., 1964). In some instances increased pulmonary airway resistance with air trapping has been demonstrated (Wright and Filley, 1951; Ayvazian, Steward, Merkel, and Frederick, 1967), though this may have been due to coexisting unrelated disease (Miller et al., 1962).

Diagnosis is difficult. If the disorder is not considered in the differential diagnosis it will not be recognized (Buechner and Strug, 1956). Relevant inquiries may elicit a history of ingestion of mineral oil. The radiological findings, though not 
diagnostic in themselves, may be helpful, especially if the lung changes are both chronic and stationary. The diagnosis can be firmly established during life by the demonstration of lipophages in sputum, in needle aspirates of lung, or by open lung biopsy (Volk et al., 1955; Buechner and Strug, 1956; Miller et al., 1962 ; Weill et al., 1964 ; Ayvazian et al., 1967 ; Hofford, 1968).

Treatment consists of stopping the ingestion of paraffin, and steroid hormones have proved to be very efficacious, resulting in marked clinical relief and, eventually, in final clearing of the lungs (Nagrath and Sapru, 1964, prednisolone; Ayvazian et al., 1967, prednisone ; Hofford, 1968, ACTH). A destroyed segment of lung may require resection to prevent recurrent infection (Schwindt et al., 1967), abscess formation and septicaemia (Cotton and Lloyd, 1960).

\section{REFERENCES}

Annotation (1951). Intrinsic and extrinsic lipoid pneumonia. Lancet, 2, 70.

Annotation (1970). Hush-hush-the secret of passing a motion. Wld Med., 5, no. 8 (Jan. 13), p. 30.

Ayvazian, L. F., Steward, D. S., Merkel, C. G., and Frederick, W. W. (1967). Diffuse lipoid pneumonitis successfully treated with prednisone. Amer. J. Med., 43, 930.

Buechner, H. A., and Strug, L. H. (1956). Lipoid granuloma of the lung of exogenous origin. Dis. Chest, 29, 402.

Cotton, R. E., and Lloyd, H. E. D. (1960). Lipid pneumonia and infection with Nocardia asteroides complicating achalasia of the cardia. J. Path. Bact., 79, 251.
Elston, C. W. (1966). Pneumonia due to liquid paraffin: with chemical analysis. Arch. Dis. Childh., 41, 428.

Forbes, G., and Bradley, A. (1958). Liquid paraffin as a cause of oil aspiration pneumonia. Brit. med.J., 2, 1566.

Freiman, D. G., Engelberg, H., and Merrit, W. H. (1940). Oil aspiration (lipoid) pneumonia in adults. A clinicopathologic study of forty-seven cases. Arch. intern. Med., 66, 11.

Hofford, J. M. (1968). Lipid pneumonia masquerading as asthma. Delaware med. J., 40, 340.

Meyers, J. B., and Griffith, R. L. (1955). Lipoid pneumonia due to prolonged ingestion of mineral oil. Dis. Chest, 27, 677.

Miller, A., Bader, R. A., Bader, M. E., Teirstein, A. S., and Selikoff, I. J. (1962). Mineral oil pneumonia. Ann. intern. Med., 57, 627.

Nagrath, S. P., and Sapru, R. P. (1964). Lipoid pneumonia: review of literature with a case report. J. Indian med. Ass., 42, 453.

Paterson, J. L. H. (1938). An experimental study of pneumonia following the aspiration of oily substances: lipoid cell pneumonia. J. Path. Bact., 46, 151 .

Pinkerton, H. (1927). Oils and fats. Their entrance into and fate in the lungs of infants and children: a clinical and pathologic report. Amer. J. Dis. Child., 33, 259.

(1928). The reaction to oils and fats in the lung. Arch. Path., 5,380 .

Rewell, R. E. (1947). Lipoid pneumonia: A pitfall in diagnosis. Brit. med. J., 1, 409.

Schwindt, W. D., Barbee, R. A., and Jones, R. J. (1967). Lipoid pneumonia. Its protean nature and clinical resemblance to carcinoma of the lung. Arch. Surg., 95, 652.

Siddons, A. H. M. (1958). Oil granuloma of the lung. Report of three cases. Brit. med. J., 1, 305.

Steinberg, I., and Finby, N. (1956). Lipoid (mineral oil) pneumonia and cor pulmonale due to cardiospasm. Amer. J. Roentgenol., 76, 108 .

Volk, B. W., Nathanson, L., Losner, S., Slade, W. R., and Jacobi, M. (1951). Incidence of lipoid pneumonia in a survey of 389 chronically ill patients. Amer. J. Med., 10, 316.

- Losner, S., Lewitan, A., and Nathanson, L. (1955). Diagnosis of lipoid pneumonia. Amer. J. Surg., 89, 158.

Wagner, J. C., Adler, D. I., and Fuller, D. N. (1955). Foreign body granulomata of the lungs due to liquid paraffin. Thorax, 10, 157.

Weill, H. Ferrans, V. J., Gay, R. M., and Ziskind, M. M. (1964). Early lipoid pneumonia. Roentgenologic, anatomic and physiologic characteristics. Amer. J. Med., 36, 370.

Wright, G. W., and Filley, G. F. (1951). Pulmonary fibrosis and respiratory function. Amer. J. Med., 10, 642. 